\title{
Thermodynamic modelling of the La-Pb Binary system
}

\author{
M.Idbenali ${ }^{1}$, C.Servant ${ }^{2}$, N.Selhaoui ${ }^{1}$ and L.Bouirden ${ }^{1}$ \\ ${ }^{1}$ Laboratoire de Thermodynamique Métallurgique et Rhéologie des Matériaux, Université Ibn Zohr, B.P. 496, \\ Dcheira, Agadir, Morocco. \\ ${ }^{2}$ Laboratoire de Physicochimie de l'Etat Solide, ICMMO, Université de Paris-Sud, 91405 Orsay Cedex France. \\ idbenalimohamed@yahoo.fr
}

\begin{abstract}
The thermodynamic modelling of the La- $\mathrm{Pb}$ binary system was carried out with the help of CALPHAD (CALculation of PHAse Diagram) method. $\mathrm{La}_{5} \mathrm{~Pb}_{3}, \mathrm{La}_{4} \mathrm{~Pb}_{3}, \mathrm{La}_{5} \mathrm{~Pb}_{4}, \alpha \mathrm{La}_{3} \mathrm{~Pb}_{4}, \beta \mathrm{La} 3 \mathrm{~Pb} 4, \mathrm{LaPb}_{2}, \mathrm{LaPb}_{3}$ have been treated as stoichiometric compounds while a solution model has been used for the description of the liquid, BCC and FCC phases. The calculations based on the thermodynamic modeling are in good agreement with the phase diagram data and experimental thermodynamic values.
\end{abstract}

Keywords: La-Pb system, phase diagram, Thermodynamic modelling, Calphad method.

\section{Introduction}

This study is part of a thermodynamic investigation of $\mathrm{M}-\mathrm{Pb}$ systems (M=Ba [1], $\mathrm{Ca}$ [2], $\mathrm{Yb}$ [3]) which is intended to give a better understanding of the constitutional properties and potential technological applications of these alloys. The present work deals with an assessment of the thermodynamic description of the $\mathrm{La}-\mathrm{Pb}$ system using the CALPHAD technique [4].

Early investigations of the La-Pb system included that of Canneri [5] who drew a diagram with only three intermetallic compounds $\mathrm{La}_{2} \mathrm{~Pb}, \mathrm{LaPb}$ and $\mathrm{LaPb}_{2}$. No structural details were given and terminal solubilities were not studied.

Later McMasters et al [6] determined the entire La$\mathrm{Pb}$ system by differential thermal analysis (DTA), metallography and X-ray diffraction (XRD). The phase diagram of McMasters et al [6] contained six intermediate phases: $\mathrm{La}_{5} \mathrm{~Pb}_{3}, \mathrm{La}_{4} \mathrm{~Pb}_{3}, \mathrm{La}_{11} \mathrm{~Pb}_{10}$, $\alpha \mathrm{La}_{3} \mathrm{~Pb}_{4}, \quad \beta \mathrm{La}_{3} \mathrm{~Pb}_{4}, \mathrm{LaPb}_{2}, \mathrm{LaPb}_{3}$. La $\mathrm{L}_{11} \mathrm{~Pb}_{10}$ existed only in the 1433 to $1623 \mathrm{~K}$ temperature range.

The maximum solubility of $\mathrm{Pb}$ in La was about 2.5 at. $\%$ at the catatectic equilibrium temperature $(\mathrm{T}=1113 \mathrm{~K})$, less than $1 \%$ at the eutectic temperature of $1048 \mathrm{~K}$ and less than $0.5 \%$ at at $\sim 973 \mathrm{~K}$. The solubility of $\mathrm{Pb}$ in $\mathrm{La}$ is about $5 \%$ at the eutectic temperature of $598 \mathrm{~K}$. The maximum solubility of $\mathrm{La}$ in $\mathrm{Pb}$ was estimated to be less than 0.1 at. $\%$ according to McMasters et al [6]. McMasters et al [7] has proposed update of their diagram. The modifications involved deletion of $\mathrm{La}_{11} \mathrm{~Pb}_{10}$, addition of $\mathrm{La}_{5} \mathrm{~Pb}_{4}$, with incongruent melting at $1623 \mathrm{~K}$.

Table 1. Symbols and Crystal Structures of the Stable Solid Phases in the (La-Pb) Alloys from [8]

\begin{tabular}{|c|c|c|c|c|c|c|}
\hline $\begin{array}{l}\text { Diagram } \\
\text { Symbol }\end{array}$ & $\begin{array}{l}\text { Composition at } \% \\
\mathrm{~Pb}\end{array}$ & $\begin{array}{l}\text { Symbol Used in } \\
\text { Thermo-Calc Data } \\
\text { File }\end{array}$ & $\begin{array}{l}\text { Pearson } \\
\text { Symbol }\end{array}$ & $\begin{array}{l}\text { Space } \\
\text { Group }\end{array}$ & $\begin{array}{l}\text { Strukturberic } \\
\text { ht Symbol }\end{array}$ & Prototype \\
\hline yLa & 0 at 2.5 & BCC_A2 & $c / 2$ & $\operatorname{Im} \overline{3} m$ & $\mathrm{~A} 2$ & W \\
\hline$\beta \mathrm{La}$ & from 0 to 1 & FCC_A1 & $c F 4$ & $F m \overline{3} m$ & A1 & $\mathrm{Cu}$ \\
\hline$\alpha \mathrm{La}$ & 0 & Dhcp & $h P 4$ & $P 6_{3} / m m c$ & $\mathrm{~A}^{\prime}$ & $\mathrm{La}$ \\
\hline $\mathrm{La}_{5} \mathrm{~Pb}_{3}$ & 37.5 & $\mathrm{La}_{5} \mathrm{~Pb}_{3}$ & $h P 16$ & $\mathrm{~Pb}_{3} / \mathrm{mcm}$ & $\mathrm{D}_{8}$ & $\mathrm{Mn}_{5} \mathrm{Si}_{3}$ \\
\hline $\mathrm{La}_{4} \mathrm{~Pb}_{3}$ & 42.9 & $\mathrm{La}_{4} \mathrm{~Pb}_{3}$ & $c / 28$ & $I \overline{4} 3 d$ & $\mathrm{D} 73$ & Anti- $\mathrm{Th}_{3} \mathrm{Ge}_{4}$ \\
\hline $\mathrm{La}_{5} \mathrm{~Pb}_{4}$ & 44.4 & $\mathrm{La}_{5} \mathrm{~Pb}_{4}$ & oP36 & Pnma & $\ldots$ & $\mathrm{Sm}_{5} \mathrm{Ge}_{4}$ \\
\hline$\alpha \mathrm{La}_{3} \mathrm{~Pb}_{4}$ & 57.1 & $\mathrm{aLa}_{3} \mathrm{~Pb}_{4}$ & & & & \\
\hline$\beta \mathrm{La}_{3} \mathrm{~Pb}_{4}$ & 57.1 & $\beta \mathrm{La}_{3} \mathrm{~Pb}_{4}$ & & & & \\
\hline $\mathrm{LaPb}_{2}$ & 66.7 & $\mathrm{LaPb}_{2}$ & & & & \\
\hline $\mathrm{LaPb}_{3}$ & 75 & $\mathrm{LaPb}_{3}$ & $c P 4$ & $P m \overline{3} m$ & $\mathrm{~L} 1_{2}$ & $\mathrm{AuCu}_{3}$ \\
\hline$(\mathrm{Pb})$ & $99.9<x(\mathrm{~Pb})<1$ & FCC_A1 & $c F 4$ & $F m \overline{3} m$ & A1 & $\mathrm{Cu}$ \\
\hline
\end{tabular}

The assessment of the La-Pb phase diagram (Fig.1) by Palenzona and Cirafici [8] is based on the investigation of [6] with modification of [7]. The equilibrium phases are: (1) the liquid, (2) the seven intermediate phases: $\mathrm{La}_{5} \mathrm{~Pb}_{3}, \mathrm{La}_{4} \mathrm{~Pb}_{3}, \mathrm{La}_{5} \mathrm{~Pb}_{4}$, $\alpha \mathrm{La}_{3} \mathrm{~Pb}_{4}, \beta \mathrm{La}_{3} \mathrm{~Pb}_{4}, \mathrm{LaPb}_{2}, \mathrm{LaPb}_{3}$. and (3) the four terminal solid solutions : $\alpha(\mathrm{La}), \beta$ (La), y (La) and $(\mathrm{Pb})$. The crystal structures of various phases are reported in Table 1. All data mentioned above are collected from studies [8]. In this paper, the thermodynamic modelling of the La-Pb system was carried out using the CALPHAD [4] method. In this work, the Gibbs energy of each phase is modelled using Parrot [9] module in the ThermoCalc software [10].

This is an Open Access article distributed under the terms of the Creative Commons Attribution-Noncommercial License (http://creativecommons.org/licenses/by-nc/3.0/), which permits unrestricted use, distribution, and reproduction in any noncommercial medium, provided the original work is properly cited. 


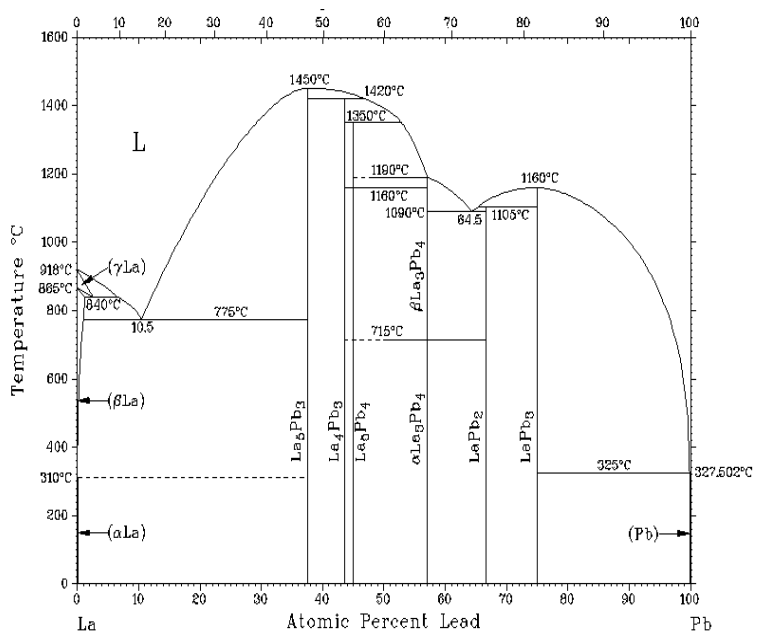

Fig.1. The La-Pb phase diagram as assessed by Palenzona et al [8]

\section{Thermodynamic Data}

The thermodynamic data available for this system are: (i) the enthalpies of formation of the intermetallic compounds determined by many authors [11-14] using various techniques (see Table 4); (ii) heat capacities of $\mathrm{LaPb}_{3}$ at constant pressure in the range 323 to $773 \mathrm{~K}$ measured by Gambino et al [15] using differential scanning calorimeter, which could be well represented by :

$$
\mathrm{Cp}=5.96+0.00183 \mathrm{~T}(\mathrm{~J} / \mathrm{g} \cdot \mathrm{atm} \cdot \mathrm{K})
$$

\section{Thermodynamic Models}

\subsection{Pure elements}

The Gibbs energy function

$G_{i}^{\phi}(T)={ }^{0} G_{i}^{\phi}-H_{i}^{S E R}(298.15 \mathrm{~K})$ for the element $i$ ( $i=\mathrm{La}, \mathrm{Pb})$ in the phase $\phi$ ( $\phi=$ Liquid, BCC_A2, DHCP or FCC_A1 ) is described by an equation of the following form:

$G_{i}^{\phi}(T)=a+b T+c \ln T+d T^{-2}+e T^{3}+f T^{7}+g T^{-9}$

Where $H_{i}^{S E R}(298.15 \mathrm{~K})$ is the molar enthalpy of the element $i$ at $298.15 \mathrm{~K}$ in its standard element reference (SER) state, FCC_A1 for Pb and DHCP for La.

In this paper, the Gibbs energy functions are taken from the SGTE compilation of Dinsdale [16].

\subsection{Solution phases}

The solution phases (( $\gamma L a),(\beta L a),(P b)$, and liquid) are modelled as substitutional solutions according to the polynomial Redlich-Kister model [17]. The Gibbs energy of one mole of formula unit of phase $\phi$ is expressed as the sum of the reference part ${ }^{r e f}{ }^{\phi}$, the ideal part ${ }^{i d} G{ }^{\phi}$ and the excess part ${ }^{x s} G{ }^{\phi}$ :

$G_{m}^{\phi}={ }^{r e f} G^{\phi}+{ }^{i d} G^{\phi}+{ }^{x s} G^{\phi}$

As used in the Thermo-calc software [10]:

$$
\begin{gathered}
{ }^{r e f}{ }_{G}^{\phi}{ }^{\phi}(T)=x_{\mathrm{La}}{ }^{0} G_{\mathrm{La}}^{\phi}+x_{\mathrm{Pb}}{ }^{0} G_{\mathrm{Pb}}^{\phi} \\
{ }^{i d} G^{\phi}=R T\left(x_{\mathrm{La}} \ln x_{L a}+x_{P b} \ln x_{P b}\right)
\end{gathered}
$$

Where: $R$ is the gas constant; $T$ is the temperature, in Kelvin; $x_{\mathrm{La}}$ and $x_{\mathrm{Pb}}$ are the mole fraction of elements $\mathrm{La}$ and $\mathrm{Pb}$, respectively.

${ }^{0} G_{\mathrm{i}}^{\phi}$ is the molar Gibbs energy of elements (i=La, $\mathrm{Pb}$ ) with the structure $\varnothing$

The excess terms of all the phases were modelled by the Redlich-Kister [17] formula.

$$
{ }^{i d}{ }_{G}^{\phi}(T)=x_{\mathrm{La}}{ }^{x} \mathrm{~Pb}\left[{ }^{0} L_{\mathrm{La}, \mathrm{Pb}}^{\phi}(T)+{ }^{1} L_{\mathrm{La}, \mathrm{Pb}}^{\phi}(T)\left(x_{L a}-x_{\mathrm{Pb}}\right)^{1}\right]
$$

With: ${ }^{i} L_{\mathrm{La}, \mathrm{Pb}}^{\phi}(T)=a_{i}+b_{i} T$

Where: ${ }^{i} L_{\mathrm{La}, \mathrm{Pb}}^{\phi}(T)$ is the $i^{\text {th }}$ interaction parameter between the elements $\mathrm{La}$ and $\mathrm{Pb}$, which is evaluated in the presented work. $a_{i}$, and $b_{i}$ are the coefficients to be optimized.

\subsection{Stoichiometric compounds:}

The Gibbs energy of the stoichiometric compound ${ }^{0} G_{A p B q}$ is expressed as follows:

${ }^{0} G_{A_{p} B_{q}}=p^{0} G_{A}+q^{0} G_{B}+a+b T$

Where ${ }^{0} G_{A}$ and ${ }^{0} G_{B}$ are the Gibbs energy of the pure elements $\mathrm{La}$ and $\mathrm{Pb}$ in the reference state DHCP and FCC respectively. $a$ and $b$ are parameters to be determined. 
Table 2. The thermodynamic parameters of the La-Pb system

\begin{tabular}{|c|c|c|}
\hline Phase & Thermodynamic Models & Parameters (units in J.mol ${ }^{-1}$. at and $\mathrm{J} / \mathrm{mol}$.at.K) \\
\hline Liquid & $(\mathrm{La}, \mathrm{Pb})_{1}$ & $\begin{array}{l}{ }^{0} L_{L a, P b}^{\operatorname{Liq}}=-206512.146+32.0683 \mathrm{~T} \\
{ }^{1} L_{L a, P b}^{L i q}=23133.1399+11.8780 T\end{array}$ \\
\hline BCC_A2 & $(\mathrm{La}, \mathrm{Pb})_{1}(\mathrm{Va})^{\underline{\underline{\underline{*}}}}{ }_{3}$ & $\begin{array}{l}{ }^{0} L_{L a, P \bar{b}}^{B C C_{-} A 2}=-112100.158+5 \mathrm{~T} \\
{ }^{1} L_{L a, P \bar{b}}^{B C C_{-} A 2}=-22305.6658+2 \mathrm{~T}\end{array}$ \\
\hline FCC_A1 & $(\mathrm{La}, \mathrm{Pb})_{1}(\mathrm{Va})_{1}$ & $\begin{array}{l}{ }^{0} L_{L a, P \bar{b}}^{F C C^{A 1}}=-111963.901+9.7822 \mathrm{~T} \\
{ }^{1} L_{L a, P \bar{b}}^{F C C_{-}{ }^{A 1}}=-23055.6288+3.5091 \mathrm{~T}\end{array}$ \\
\hline $\mathrm{La}_{5} \mathrm{~Pb}_{3}$ & $(\mathrm{La})_{0.625}:(\mathrm{Pb})_{0.375}$ & $\begin{array}{l}{ }^{0} G_{L a: P b}^{L a 5 P 3}=0.375{ }^{0} G_{P b}^{F C C_{-} A 1}+0.625{ }^{0} G_{L a}^{D H C P} \\
-68640.6350+10.9894 T\end{array}$ \\
\hline $\mathrm{La}_{4} \mathrm{~Pb}_{3}$ & $(\mathrm{La})_{0.571}:(\mathrm{Pb})_{0.429}$ & $\begin{array}{l}{ }^{0} G_{L a: P b}^{L a 4 P b 3}=0.429{ }^{0} G_{P b}^{F C C_{-} A 1}+0.571{ }^{0} G_{L a}^{D H C P} \\
-73248.6637+12.2512 \mathrm{~T}\end{array}$ \\
\hline $\mathrm{La}_{5} \mathrm{~Pb}_{4}$ & $(\mathrm{La})_{0.555}:(\mathrm{Pb})_{0.445}$ & $\begin{array}{l}{ }^{0} G_{L a: P b}^{L a 5 P b 4}=0.445{ }^{0} G_{P b}^{F C C_{-}{ }^{A 1}}+0.555{ }^{0} G_{L a}^{D H C P} \\
-72824.2820+11.8035 T\end{array}$ \\
\hline $\mathrm{aLa}_{3} \mathrm{~Pb}_{4}$ & $(\mathrm{La})_{0.429}:(\mathrm{Pb})_{0.571}$ & $\begin{array}{l}{ }^{0} G_{L a: P b}^{\alpha L a 3 P b 4}=0.571{ }^{0} G_{P b}^{F C C_{-}{ }^{A 1}}+0.429{ }^{0} G_{L a}^{D H C P} \\
-69475+10.41329 \mathrm{~T}\end{array}$ \\
\hline$\beta \mathrm{La}_{3} \mathrm{~Pb}_{4}$ & $(\mathrm{La})_{0.429}:(\mathrm{Pb})_{0.571}$ & $\begin{array}{l}{ }^{0} G_{L a: P b}^{\beta L a 3 P b 4}=0.571{ }^{0} G_{P b}^{F C C_{-}{ }^{A 1}}+0.429{ }^{0} G_{L a}^{D H C P} \\
-69459.0803+10.3971773 T\end{array}$ \\
\hline $\mathrm{LaPb}_{2}$ & $(\mathrm{La})_{0.333}:(\mathrm{Pb})_{0.667}$ & $\begin{array}{l}{ }^{0} G_{L a: P b}^{L a P b 2}=0.667{ }^{0} G_{P b}^{F C C}{ }_{-}^{A 1}+0.333{ }^{0} G_{L a}^{D H C P} \\
-66802.1321+11.2980 T\end{array}$ \\
\hline $\mathrm{LaPb}_{3}$ & $(\mathrm{La})_{0.25}:(\mathrm{Pb})_{0.75}$ & $\begin{array}{l}{ }^{0} G_{L a: P b}^{L a P b 3}=0.75{ }^{0} G_{P b}^{F C C_{-} A 1}+0.25{ }^{0} G_{L a}^{D H C P} \\
-64452.7837+12.5374 T\end{array}$ \\
\hline
\end{tabular}

* (Va) for vacancy

\section{Results and discussions}

The parameters of La-Pb binary system were optimized using the Parrot module [9] in the ThermoCalc [10] software. This program is able to take various kinds of experimental data in one operation and minimizes the sum of squared error. Each of the selected data values is given a certain weight, which is chosen and adjusted based on the data uncertainties given experimentally. No enthalpy of mixing of the liquid was available in the literature. In the present parameter optimization procedure we first imposed the conditions $\mathrm{d}^{2} \mathrm{G} / \mathrm{dx}^{2}>0$ for modeling the liquid phase to avoid the appearance of an unwanted inverted miscibility gap in that phase during the phase diagram calculation as recommended in [18-21]. Therefore we grid the space in $x$ ( every 0.05 at.) and $T$ (every 25K) $(600<T<5000 \mathrm{~K})$. The phase boundary data reported by [8] and thermodynamic data were used. Then the thermodynamic parameters for the intermediate phases were optimized based on the enthalpies of formation of the intermetallic compounds measured by [14] and the invariant equilibrium from [8]. All the parameters were evaluated and listed in Table 2.

The calculated phase diagram is shown in Fig. 2 . The experimental and calculated temperatures of the invariant reactions are compared in Table 3. The enthalpy of formation of the intermetallic compounds calculated with the experimental values is listed in Table 4 and presented in Fig. 4. A satisfactory agreement is noted. Fig. 3 shows the calculated molar heat capacity of LaPb3 at different temperatures with the experimental data. It can be seen that the calculated results agree well with the experimental values [15]. The singular point at $600.61 \mathrm{~K}$ corresponds to the joining temperature of two thermodynamic descriptions of pure element $\mathrm{Pb}$ for different temperature ranges in [16] .

As first stated by Chen et al [20], we verified that when the liquid phase is suspended, the 
intermetallic compounds are no more stable at very

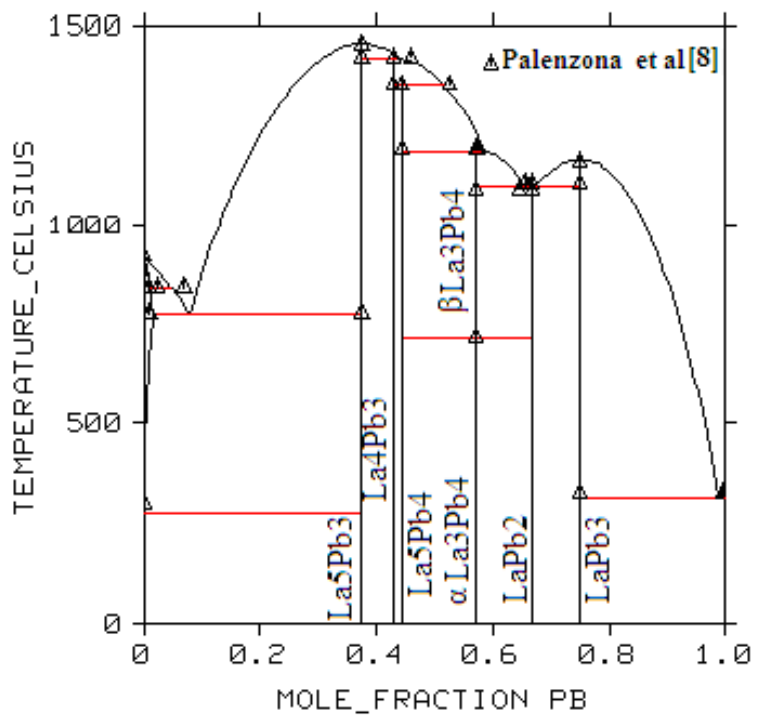

Fig.2.Calculated La-Pb phase diagram with data from [8] high temperatures, because the enthalpy of

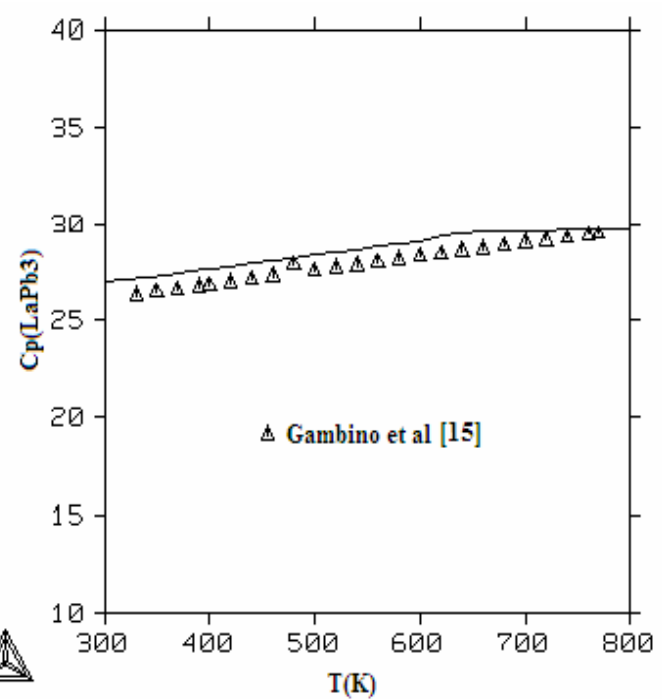

Fig.3. Calculated molar heat capacity of $\mathrm{LaPb}_{3}$ at different temperatures, together with experimental data

Table 3. Invariant reactions in the La-Pb System.

\begin{tabular}{|c|c|c|c|c|}
\hline \multirow{2}{*}{ Reaction } & \multicolumn{2}{|c|}{ [8] } & \multicolumn{2}{|c|}{ This work } \\
\hline & $\mathrm{T}(\mathrm{K})$ & $x(\mathrm{~Pb})$. & $\mathrm{T}(\mathrm{K})$ & $x(\mathrm{~Pb})$ \\
\hline$\alpha \mathrm{L} a \Leftrightarrow \beta \mathrm{La}$ & 583 & 0 & $550^{*}$ & 0 \\
\hline yLa $\Leftrightarrow \beta L a+l i q$ & 1113 & $\begin{array}{c}\text { yLa } 0.025 \\
\beta \text { La } 0.010 \\
\text { liq } 0.070\end{array}$ & 1113 & $\begin{array}{l}\text { YLa } 0.013 \\
\beta \text { La } 0.008 \\
\text { liq } 0.046\end{array}$ \\
\hline $\mathrm{Liq} \Leftrightarrow \beta \mathrm{La}+\mathrm{La}_{5} \mathrm{~Pb}_{3}$ & 1048 & $\begin{array}{c}\beta \text { La } 0.010 \\
\text { Liq } 0.100\end{array}$ & 1046 & $\begin{array}{c}\text { BLa } 0.016 \\
\text { Liq } 0.080\end{array}$ \\
\hline Liq $\Leftrightarrow \mathrm{La}_{5} \mathrm{~Pb}_{3}$ & 1723 & 0.375 & 1726 & 0.375 \\
\hline $\mathrm{La}_{4} \mathrm{~Pb}_{3} \Leftrightarrow \mathrm{Liq}+\mathrm{La}_{5} \mathrm{~Pb}_{3}$ & 1693 & Liq 0.460 & 1691 & Liq 0.438 \\
\hline $\mathrm{La}_{5} \mathrm{~Pb}_{4} \Leftrightarrow \mathrm{Liq}+\mathrm{La}_{4} \mathrm{~Pb}_{3}$ & 1623 & Liq 0.520 & 1623 & Liq 0.514 \\
\hline$\beta \mathrm{La}_{3} \mathrm{~Pb}_{4} \Leftrightarrow L i q+\mathrm{La}_{5} \mathrm{~Pb}_{4}$ & 1463 & Liq 0.570 & 1457 & Liq 0.587 \\
\hline$\beta L a_{3} \mathrm{~Pb}_{4} \Leftrightarrow \alpha \mathrm{La}_{3} \mathrm{~Pb}_{4}$ & 988 & & 981 & \\
\hline $\mathrm{Liq} \Leftrightarrow \beta \mathrm{La}_{3} \mathrm{~Pb}_{4}+\mathrm{LaPb}_{2}$ & 1363 & Liq 0.640 & 1371 & Liq 0.656 \\
\hline $\mathrm{Liq}+\mathrm{LaPb} 3 \Leftrightarrow \mathrm{LaPb} 2$ & 1378 & Liq 0.650 & 1372 & Liq 0.674 \\
\hline Liq $\Leftrightarrow \mathrm{LaPb}_{3}$ & 1433 & & 1437 & \\
\hline Liq $\Leftrightarrow \quad(P b)+\mathrm{LaPb}_{3}$ & 598 & $\begin{array}{cc}(\mathrm{Pb}) & 0.999 \\
\text { Liq } 0.995\end{array}$ & 588.3 & $\begin{array}{cc}(\mathrm{Pb}) & 1.000 \\
\text { Liq } & 0.988\end{array}$ \\
\hline
\end{tabular}

- $\quad$ from [16]

formation of these compounds is approximately the same but their entropy is negative (i.e. $b>0$ in Eq. 8) but less negative than $-12 \mathrm{~J} / \mathrm{mol} . \mathrm{K}$. In Fig. 9, therefore the computed phase diagram gives the BCC_A2 phase stable. At high temperatures, only this solid solution is calculated on the whole $\mathrm{Pb}$ composition range and not the FCC_A1 one in the $\mathrm{Pb}$-rich region. This is due to the power series in terms of temperature for the $\mathrm{Pb}$ element in the BCC A2 state which becomes more stable compared to the FCC A1 state around $2000 \mathrm{~K}$ and for higher temperatures [16]. 
Table 4. Calculated and measured enthalpies formation of the intermetallic compounds.

\begin{tabular}{|c|c|c|c|}
\hline Phase & Enthalpy of formation $\mathrm{kJ} / \mathrm{mol}$ & Technique used & Ref \\
\hline \multirow{5}{*}{$\mathrm{LaPb}_{3}$} & -51.5 & Dynamic differential calorimetric & [11] \\
\hline & -57.3 & Differential direct isoperibol calorimeter & [12] \\
\hline & -59.1 & Emf & [13] \\
\hline & -49 & Semi empirical model of Miedema & [14] \\
\hline & -64.4 & optimization & This work \\
\hline \multirow{3}{*}{$\mathrm{LaPb}_{2}$} & -60.3 & Differential direct isoperibol calorimeter & {$[12]$} \\
\hline & -63 & Semi empirical model of Miedema & [14] \\
\hline & -66.7 & optimization & This work \\
\hline $\mathrm{aLa}_{3} \mathrm{~Pb}_{4}$ & -69.4 & optimization & This work \\
\hline \multirow{3}{*}{$\beta \mathrm{La}_{3} \mathrm{~Pb}_{4}$} & -64 & Differential direct isoperibol calorimeter & [12] \\
\hline & -72 & Semi empirical model of Miedema & [14] \\
\hline & -69.4 & optimization & \\
\hline \multirow{3}{*}{$\mathrm{La}_{5} \mathrm{~Pb}_{4}$} & -69.1 & Differential direct isoperibol calorimeter & [12] \\
\hline & -72 & Semi empirical model of Miedema & [14] \\
\hline & -72.7 & optimization & This work \\
\hline \multirow{3}{*}{$\mathrm{La}_{4} \mathrm{~Pb}_{3}$} & -69.9 & Differential direct isoperibol calorimeter & [12] \\
\hline & -71 & Semi empirical model of Miedema & [14] \\
\hline & -73.1 & optimization & This work \\
\hline \multirow{3}{*}{$\mathrm{La}_{5} \mathrm{~Pb}_{3}$} & -72.2 & Differential direct isoperibol calorimeter & [12] \\
\hline & -65 & Semi empirical model of Miedema & [14] \\
\hline & -68.5 & optimization & This work \\
\hline
\end{tabular}

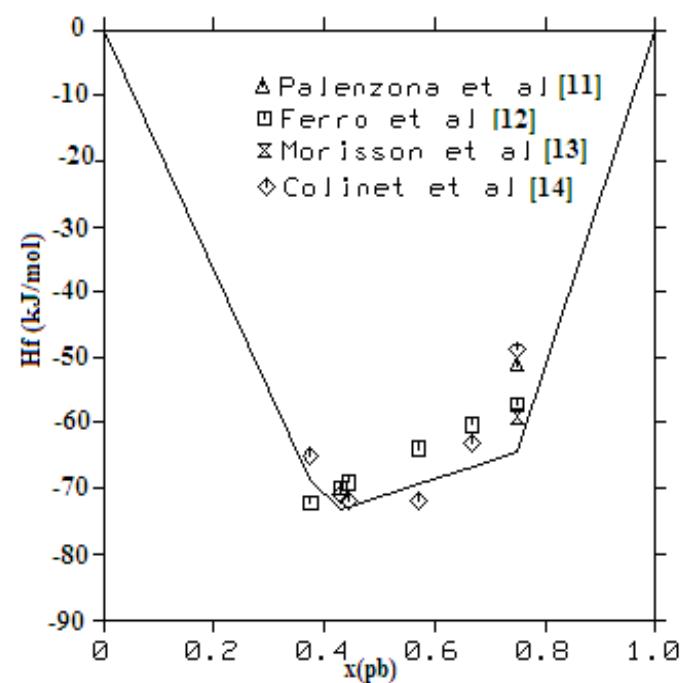

Fig. 4. Calculated and measured enthalpies of formation of the intermetallic compounds

\section{Conclusion}

A consistent set of thermodynamic parameters of the different phases of the La-Pb binary system has been optimized. The computed values are in good

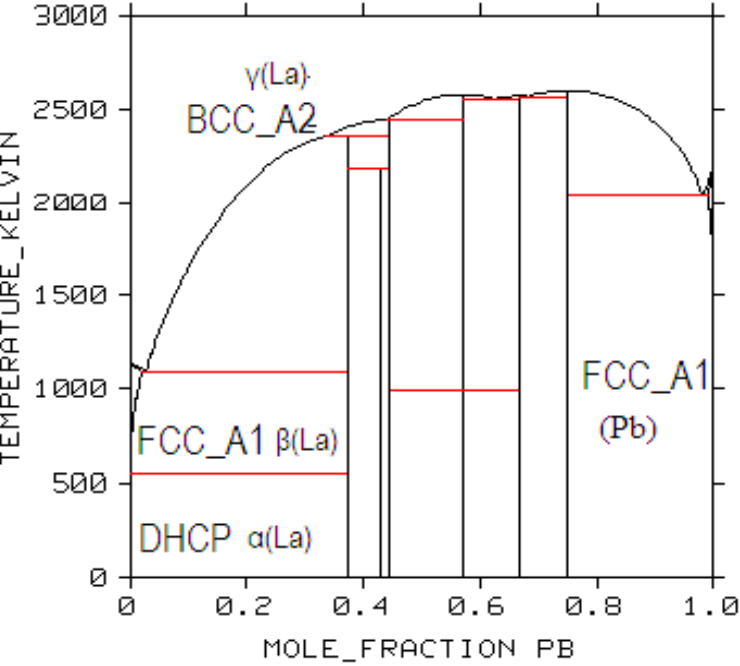

Fig.5. Calculated La-Pb phase diagram when the liquid phase is suspended

agreement with the experimental data. Further thermodynamic determinations, in particular the 


\section{References}

[1] M. Idbenali, C. Servant, N. Selhaoui, L. Bouirden, CALPHAD, 31 (2007) 479.

[2] M. Idbenali, C. Servant, N. Selhaoui, L. Bouirden, CALPHAD, 32 (2008) 64.

[3] M. Idbenali, C. Servant, N. Selhaoui, L. Bouirden, CALPHAD, 33 (2009) 570.

[4] L. Kaufman and H. Bernstein, Computer Calculations of Phase Diagrams, Academic Press, New-York, NY, (1970).

[5] G. Canneri, Metall. Ital, 23, 805-808 (1931) in Italian. (Equi. diagram; Experimental)

[6] O.D. McMasters, S.D. Soderquist, and K.A. Gschneider, Jr., ASM Trans . Quart., 61, 435-441 (1968).

[7] O.D. McMasters and K.A. Gschneidner, jr., J.Less-Common Met., 45, 275-281 (1976) .(Equi. Diagram, Crys Structure; Experimental)

[8] A. Palenzona and S. Cirafici ; J. Phase Equilibria Vol.13, 42-49 (1992)

[9] B. Jansson Thesis, Royal Institute of Technology, Stockholm; 1984

[10] B. Sundman, J-O. Andersson, CALPHAD 9 (1985) 153-190.

[11] A. Palenzona and S. Cirafici, Thermochim, Acta, 6, 455-460 (1973)

[12] R. Ferro, A. Orsese, R. Capelli, and S. Delfino, Z.Anorg.Allg.Chem, 413,279-284 (1975).

[13] A. Morisson, C. Petot, and A. Percheron-Guegan, Thermochim.Acta, 101, 177-184 (1986)

[14] C. Colinet, A. Pasturel, A. Percheron-Guegan, and J.C. Achard, J.Less-Common Met, 102, $239-249$ (1984)

[15] M. Gambino, P. Rebouillon, J.P. Bros, G. Borozone, G. Caccicamani, and R. Ferro, J. Less-Common Met, 154, 195-205(1989) in French. (Thermo;Experimental)

[16] A.T. Dinsdale, Calphad 15 (1991) 317.

[17] O. Redlich and A. Kister, Ind. Eng. Chem, 40, 345-348 (1948).

[18] R. Arroyave and Z.K. Liu, Calphad 28 (2006) 1-13.

[19] C.H.P.LUPIS, Chemical Thermodynamics of Materials,(1983)

Elsevier Science Publishers B.V,P.O. Box 211,1000 AE Amsterdam, the Netherlands.

[20] S.L. Chen, S. Daniel, F. Zhang, Y.A. Chang, W.A. Oates and R. Schmid-Fetzer, J. Phase Equilibria, 22 (2001) 373-378

[21] K.C. Kumar, P. Wollants, J. Alloys Compds, 320 (2001), 189-198. 